\title{
THE HEAT OF FORMATION OF WATER AND THE HEATS OF COMBUSTION OF METHANE AND CARBON MO- NOXIDE. A CORRECTION
}

\author{
By Frederick D. Rossini
}

The data on the heat of formation of water and the heats of combustion of methane and carbon monoxide, which were obtained in this laboratory last year, ${ }^{1}$ were reduced to a constant pressure of 1 atmosphere by means of the formula used by Schuller and Wartha ${ }^{2}$ for this purpose. This procedure is incorrect. No reduction of the present data, or of the data of Schuller and Wartha, to 1 atmosphere is necessary because the pressure coefficient of the heat of these reactions is negligibly small.

For gaseous reactions occurring at constant pressure, the change of the heat of reaction with pressure is zero when the reactants and the products are "ideal" gases. For real gases at pressures near 1 atmosphere, the change in the heat content with pressure is entirely negligible (of the order of 0.001 calorie per mole per $\mathrm{mm} \mathrm{Hg}$ ) in comparison with the heat of reaction. For a liquid or a solid, the change in heat content with pressure is also negligible.

Although the error which results from the procedure used is significant for some of the individual experiments, the final "best" values for the heat of formation of water and for the heats of combustion of methane and carbon monoxide are affected to a neglibible extent. Therefore, the final "best" values for the heat of these reactions are not changed, but the statements made in the original papers with regard to the change with pressure of the heat of these reactions should be deleted.

In the papers under consideration, ${ }^{3}$ the following parts of the text are incorrect and should be omitted:

Page 23. The second paragraph.

Page 38. The paragraph beginning near the bottom of the page.

Page 49. The words in the last sentence of each of the first two paragraphs which give the pressure coefficient.

In Table 2, page 24, Table 4, page 26, Table 7, page 29, Table 4, page 43 , and Table 8 , page 47 , the corrections shown in the column headed "presssure correction to 1 atmosphere" should not be made.

1 Rossini, B. S. Jour. Research, 6, pp. 1, 36; 1931.

2 Schuller and Wartha, Ann. Physik, 2, p. 378; 1877.

3 See footnote 1. 
The correct mean values of the various series of experiments, with their average deviations, are:

\begin{tabular}{|c|c|c|}
\hline & Former mean & $\begin{array}{c}\text { Corrected } \\
\text { mean }\end{array}$ \\
\hline $\begin{array}{l}\text { Water, Set I, Table 2, page } 24 \\
\text { Water, Set II, Table 4, page } 26, \text { Table } 7 \text {, page } 29.9 \\
\text { Water (Schuller and Wartha), } \\
\text { Methane, Table 4, page } 43 \\
\text { Carbon monoxide, Table } 8 \text {, page } 47,\end{array}$ & $\begin{array}{l}285,749 \pm 53 \\
285,781 \pm 28 \\
285,890 \pm 38 \\
889,700 \pm 218 \\
282,925 \pm 109\end{array}$ & $\begin{array}{l}285,756 \pm 43 \\
285,788 \pm 23 \\
285,850 \pm 50 \\
889,720 \pm 230 \\
282,938 \pm 110\end{array}$ \\
\hline
\end{tabular}

Washington, June 8, 1931. 